\title{
"Interpretar as interpretações" aspectos teóricos da História Intelectual de Michel Foucault ${ }^{*}$
}

\author{
"Interpreting the interpretations" \\ theoretical aspects of Michel Foucault's Intellectual History
}

\author{
MARCOS ANTÔNIO LOPES \\ Professor do Departamento de História \\ Universidade Estadual de Londrina \\ Pesquisador do CNPq \\ malopes@uel.br / marcos.lopes@pq.cnpq.br
}

\begin{abstract}
RESUMO Com frequência tem sido defendido o argumento de que não será mais tarefa tão relevante saber o que nos diz uma obra de pensamento, na forma como foi fixada por seu autor num momento bem definido de sua experiência histórica datada. Desse modo, um texto filosófico desvincularse-ia de seu criador, passando a "pertencer" a diferentes e sucessivas comunidades de leitores no espaço e no tempo. Com efeito, o problema da intencionalidade autoral tem perdido relevância para a pesquisa histórica das ideias. Se não há mais propriamente autor na cena de processos intelectuais, desaparecem com ele as questões relativas ao contexto de produção de textos, as referências ao lugar específico de elaboração de uma obra. Este artigo é uma tentativa de análise de alguns aspectos centrais das teorias interpretativas de textos, com ênfase nas contribuições teóricas de Michel Foucault para a História das Ideias.
\end{abstract}

Palavras-chave autores e leitores, teorias da interpretação de textos, pensamento histórico contemporâneo

* $\quad$ Artigo recebido em: 22/11/2011. Aprovado em: 13/01/2012. 
ABSTRACT The argument of it is not relevant to know what a work of human mind, in the form as it was first fixed by its author in a specific moment of his historical experience, has been quite disseminated. Thus, a philosophical text would be independent of its creator; It would "belong" to different and successive communities of readers in the space and the time. The problem of the authorial intentionality has lost relevance for the field of History of the ideas. If an author lacks in the scene of intellectual processes, important issues concerning to the context of production of texts, the references to the specific place of elaboration of an intellectual work and other important questions disappear with him. This article consists of an attempt to analyze central aspects of interpretative theories of texts, with an emphasis in Michel Foucault's theoretical contributions for the History of Ideas.

Keywords authors and readers, theories of interpretation of texts, contemporary historical thought

Tomada num sentido forte e irônico, a pretensão que tudo é texto pode ser lida como estando a dizer: faz tanto sentido dizer que os átomos são simplesmente textos de Demócrito como dizer que Demócrito é meramente uma coleção de átomos. Isto é assim porque ambos os lemas são tentativas para dar a um vocabulário um estatuto privilegiado, e são portanto igualmente disparatados.

Richard Rorty

Michel Foucault atém-se aos limites do social, sem nunca enveredar por uma história social que busque restaurar uma coerência global da sociedade ocidental. Nesse plano, ele já se situa no terreno privilegiado do estruturalismo, que atribui à esfera do discursivo uma autonomia máxima em relação às contingências sociais.

François Dosse

O tema da interpretação de textos, as concepções inovadoras de Foucault acerca da questão, e mais os problemas delas decorrentes no debate teórico contemporâneo formam um campo fértil para discussão. ${ }^{1} \mathrm{E}$

1 Há alguns anos publiquei o texto A história das ideias segundo Michel Foucault e Quentin Skinner (Mediações, Londrina, PR, v.9, n.1, 2004, p.83-99), do qual este ensaio é um desdobramento. Revisitando meu artigo anterior, achei por bem recuperar e recompor algumas passagens que me pareceram complementares à atual discussão. Como tais passagens foram reescritas (algumas até reformuladas com alteração de sentido) e inseridas dispersamente aqui, não indico suas ocorrências remetendo os interessados a www.uel.br/revistas/uel/index.php/mediacoes; acesso em 13 dez. 2011. Sou muitíssimo grato ao colega Alexandre Avelar, que se dispor a ler e a criticar este texto. Este texto é dedicado a meu amigo Marcos Alexandre Nalli que, talvez por discordar respeitosamente de quase tudo que aqui vai, não desejou emitir opinião prévia a respeito. 
fica difícil dimensionar os efeitos da obra de Foucault sem avaliar algumas das polêmicas que ela gerou. ${ }^{2} \mathrm{E}$ mais ainda porque alguns de seus simpatizantes demonstram possuir uma percepção isolacionista do pensamento histórico de Foucault no quadro geral das ciências sociais, mormente na quadra dos anos 1980-90, quando a obra do pensador francês já havia se tornado alvo de intensas discussões, com prós e contras disparados em profusão. O realce conferido à figura do autor e o esforço em desvendar suas possíveis intenções em dado momento de suas experiências como ator social são perspectivas que sempre estiveram no primeiro plano da interpretação de textos. Mas tal orientação teórica, por longo tempo consagrada como bem estabelecida tradição interpretativa, repentinamente passou a sofrer os ataques de uma concorrência cada vez mais numerosa e imaginativa. Com efeito, a partir dos finais dos anos 1960 e, de maneira mais evidente, ao longo das três décadas subsequentes, uma série de críticas desafiadoras foi desferida contra as várias espécies de análises que avaliavam textos tomando como fundamentos aspectos extratextuais. As teorias da interpretação textual vinculadas às tendências do denominado pós-estruturalismo passaram a indagar quais formas de abordagem tornariam possível estabelecer contato com uma mente situada por vezes num ponto muito remoto do passado. ${ }^{3}$

Concluindo pela impossibilidade de tal intento, esses teóricos admitiam que o acesso às intenções de um autor perdido no tempo era empresa difícil e, a rigor, desprovida de importância. Em seu plano de análise textual, Foucault levou em conta a necessidade de abordar as considerações autorais em bloco, levando-se em conta o que possuíam como aspectos específicos. ${ }^{4}$ De fato, as teorias pós-estruturalistas de interpretação de textos não se ocupam de episódios situados num dado tempo histórico e que utilizam o texto como instrumento de comunicação com o seu mundo. Como se referiu Pierre Boudieu, a empresa interpretativa passa por uma forma de "leitura interna" que leva em conta o texto nele mesmo, por seu próprio valor de

2 Um rápido retrato do autor está estampado em: BRIGGS, Asa. Foucault, Michel (1926-84). In: . (ed.). The Longman Encyclopedia. Londres: Penguin Books, 1990. Para um perfil biográfico em profundidade, ver: ERIBON, Didier. Michel Foucault. São Paulo: Companhia das Letras, 1990. Acerca da diversidade das reflexões teóricas do pensador francês, e de problemas e possibilidades para o campo da pesquisa histórica, ver os textos de: FLORENCE, Maurice. Foucault, Michel. In: HUISMAN, Denis. (org.). Dicionário dos filósofos. São Paulo: Martins Fontes, 2001; e DOSSE, François. O desvario da razão: a obra de Michel Foucault. In: _. História do estruturalismo: 0 campo do signo, 1945/1966. São Paulo/Campinas,SP: Ensaio/Editora da Unicamp, 1992, v.1.

3 As opiniões críticas emitidas pelo historiador norte-americano David Harlan são extensas e muito esclarecedoras acerca das oposições teóricas entre textualistas e contextualistas. Ver: Harlan, David. A história intelectual e o retorno da literatura. In: RAGO, Margarete e GIMENES, Rogério. (orgs.). Narrar o passado, repensar a história. Campinas, SP: IFCH, 2000.

4 Em suas próprias palavras, "os enunciados devem aí ser tratados em massa e segundo o que têm em comum sua singularidade de acontecimento pode ser neutralizada; perdem importância também a identidade de seu autor, o momento e o lugar de seu aparecimento". FOUCAULT, Michel. A arqueologia do saber. Rio de Janeiro: Forense Universitária, 2007, p.161s. Acerca do tema, ver as análises de: WINDERS, James. Michel Foucault (1926-1984). In: DAILEADER, Philip e WHALEN, Philip. (ed.). New Historical Writing in Twentieth-Century France. French Historians (1900-2000). Chichester: Blackwell Publishing, 2010; e COMPAGNON, Antoine. O demônio da teoria: literatura e senso comum. Belo Horizonte: Editora UFMG, 1999 
testemunho. Isso é bastante para constituí-lo como elemento autossuficiente. Desembaraçar uma verdade específica embrulhada no texto é de fato fazer abstração dos elementos que ficam dispostos no entorno, o que não é decisivo. ${ }^{5}$ Nesse plano da análise interpretativa verifica-se um considerável impulso na via da neutralização do valor dos acontecimentos como vestígios de história. Acontecimentos podem não ser tão eloquentes como se pensa comumente. Portanto, nada mais relevante do que as práticas discursivas geradas pelos eventos históricos. Dessa perspectiva deriva o empenho em debruçar-se sobre camadas sequenciais de desdobramentos derivados do pensamento. A ideia de descobrir e apontar práticas discursivas, em um padrão de regularidade que distinga o exercício comum das mesmas pelos predecessores mais inventivos, bem como por parte de sucessores pouco criativos, é o que constitui o cerne da empresa exegética. ${ }^{6}$ É assim que o "método" interpretativo do autor de A arqueologia do saber ocupa-se, sincrônica e diacronicamente, com as "camadas ininterruptas de efeitos" produzidos pelo pensamento, sempre procurando ressaltar "a regularidade de uma prática discursiva que é exercida, do mesmo modo, por todos os seus sucessores menos originais, ou por alguns de seus predecessores". ${ }^{7}$ Como afirma Foucault acerca da noção de temporalidade presente em seu "método" arqueológico, "Longe de ser indiferente à sucessão, a arqueologia demarca vetores temporais de derivação". ${ }^{8}$ Linguagem bastante complexa, diga-se de passagem. ${ }^{9}$ Descrente em um método original criado por si mesmo, ele disparou em entrevista concedida nos meados dos anos 1970:

Não, a arqueologia do saber não é um livro de metodologia. Não tenho um método que aplicaria, do mesmo modo, a domínios diferentes. Ao contrário, diria que é um mesmo campo de objetos, um domínio de objetos que procuro isolar, utilizando instrumentos encontrados ou forjados por mim, no exato momento em que faço minha pesquisa, mas sem privilegiar de modo algum o problema do método. ${ }^{10}$

Decerto que ocorrências históricas concretas, mormente as que produziram qualquer espécie de impacto em seu tempo (o Holocausto em meio às

5 Cf. BOURDIEU, Pierre. A leitura: uma prática cultural. Debate entre Pierre Bourdieu e Roger Chartier. In: CHARTIER, Roger. (org.). Práticas de leitura. São Paulo: Estação Liberdade, 2000, p.233.

6 Ver a propósito: FOUCAULT, Michel. A arqueologia do saber, p.165.

7 FOUCAULT, Michel. A arqueologia do saber, p.165. Segundo a caracterização da obra realizada por James Winders, "A theoretical exercise in intellectual history, L'Archéologie du savoir (...), published in 1969, was an exercise in taking stock of his intelectual career to date. In this self-critical essay, Foucault considers the archaeological method he had fashioned and hints at the departure he was about to inaugurate. Mindful of the commonly held assumption that he belonged in the structuralist camp, Foucault attempted to describe in some detail his own particular approach to language - the discourses - through which he sifted in the archaeological enterprise he contrasted with an outmoded 'history of ideas'”. WINDERS, James. Michel Foucault (1926-1984), p.258. Ver também as considerações de: MACHADO, Roberto. Ciência e saber: a trajetória da arqueologia de Michel Foucault. Rio de Janeiro: Graal, 1981.

8 FOUCAULT, Michel. A arqueologia do saber, p.193.

9 Sobre escrita e estilo ver: CASTRO, Edgardo. Vocabulário de Michel Foucault: um percurso pelos seus temas, conceitos e autores. Belo Horizonte: Autêntica, 2009

10 FOUCAULT, Michel. Poder e saber (1977). In:__. Ditos e escritos. Rio de Janeiro: Forense Universitária, 2006, p.229. 
operações militares da Segunda Guerra Mundial, por exemplo), dificilmente teriam sua realidade negada (o que não deixa de ocorrer esporadicamente). Mas as concepções que delas emergem são muito relevantes para que não assumam logo um lugar de destaque na mira do intérprete. Por isso mesmo as interpretações que se acumulam ao redor de acontecimentos históricos, por muito que possuam incontestável relevo, podem até lançar sombra sobre os próprios fatos, diluindo sua importância. Como ressaltam alguns de seus comentadores, mormente aqueles que não se inclinam a assimilar ou mesmo a admitir as propostas interpretativas de Michel Foucault no plano de uma história intelectual, não há procedimentos metodológicos que se possa identificar como coordenadas palpáveis para a pesquisa. E quando os historiadores de formação e de ofício pressentem o esoterismo de sua linguagem e percebem a sua queda para a redução do valor das provas na reflexão sobre acontecimentos fartos em evidências, a indisposição quanto à empresa analítica foucaultiana tende a acentuar-se. Nesse sentido, o hermetismo linguístico e o filosofismo o colocam à margem de um padrão considerado como o de uma normalidade mais confortável. De fato, o pensamento histórico de Foucault pode ser frequentemente percebido como portador de intensidades difíceis de serem assimiladas.

Como já afirmado, as complexidades que envolvem o trabalho da interpretação de textos limitam a importância da figura histórica do autor como peça estratégica do esforço de análise. ${ }^{11} \mathrm{E}$ isso porque há muito se eleva outra figura considerada de importância estratégica. Com efeito, o leitor ocupa um espaço nada negligenciável no plano da definição de sentidos dos textos, o que pode ser observado desde tempos bem recuados na história das criações intelectuais. Há quem defina a figura do autor não apenas como artífice da criação de um texto, mas a própria fonte de sua possível autoridade, a ser consolidada pelos valores contidos e reconhecidos em dada reflexão. A natureza do leitor, bem como o gênero de sua atividade, consiste em ocupar-se daquilo que foi produzido e colocado ao alcance dos que se encontram em condições de compreender, assimilar e exercer a crítica dos frutos da autoria. ${ }^{12}$ Nesse ponto pode-se distinguir com maior nitidez a importância conferida por Michel Foucault à por ele denominada "instância do sujeito criador". Em seu gênero de abordagem de texto esse sujeito não pode firmar-se como figura de expressão e sequer funda os pilares que transferem padrão de unidade a um texto. A lógica de tal argumento ancora-se no princípio analítico de afastamento das próprias condições históricas de produção de uma obra de pensamento. As singularidades de um discurso produzido por assim dizer "a quente", ou seja, cercado pelas condições que viabilizaram a sua emergência num momento

11 Ver: FOUCAULT, Michel. O que é um autor? (1969). In: . . Ditos e escritos, p.265-298.

12 Muito perspicazes a respeito do assunto as reflexões de: BOURDIEU, Pierre. A leitura: uma prática cultural, p.232. 
histórico datado, não constituem objeto de interesse. A descoberta e o "reencontro" com a identidade primeva de um acontecimento ficam relegados à preocupação com a variedade daquilo que foi dito sucessivamente a seu respeito. ${ }^{13} \mathrm{Em}$ complemento às considerações do autor, acrescente-se que, em sua abordagem histórica, apagam-se, ou ao menos se contraem, noções bastante arraigadas no campo da história das ideias tradicional como as vinculadas a livro ou a conjunto de obra - concebidas por um ente datado. ${ }^{14}$ Tal evanescência do sujeito se deve à consideração foucaultiana de que há relações vinculantes entre os textos, em remissões mútuas bastante complexas, porque se instauram em meio a regras associadas em uma época dada. Importa então perceber a tessitura de tais relações dos textos, mas não o papel da autoria. Como observou Hervé Martin, na visão de Foucault os textos repousam largamente no vasto território do que já foi dito. ${ }^{15}$ Michel Foucault procurou evidenciar os pontos que se deveria evitar no gênero de história que praticava. ${ }^{16}$ Recusando balizas como criação, unidade e originalidade, ${ }^{17}$ seu programa de trabalho exerceu e ainda exerce considerável influência sobre os historiadores brasileiros. ${ }^{18}$

Os textos teórico-metodológicos de Roger Chartier muito se ocupam das variedades da leitura e das complexidades da interpretação histórica. Nesse plano, a variações dos olhares exercem um domínio insuperável. ${ }^{19} \mathrm{~A}$ multiplicidade das formas de percepção dos sentidos presentes em textos abre caminho para a diversidade dos sentidos atribuídos a eles, e mais ainda quando tomados em perspectivas já amplamente situadas fora da moldura original (leia-se o lugar próprio de elaboração). Decerto que dada obra de pensamento, podendo ser "consumida" por posteridades sucessivas de leitores, um dia tencionou expressar, por vontade autônoma de

13 Segundo o original, "a arqueologia não procura reconstituir o que pôde ser pensado, desejado, visado, experimentado, almejado pelos homens no próprio instante em que proferiram o discurso. (...) Em outras palavras, não tenta repetir o que foi dito, reencontrando-o em sua própria identidade. (...) Não é nada diferente de uma reescrita". FOUCAULT, Michel. A arqueologia do saber, p.160.

14 "Não é legítimo, pois, indagar à queima-roupa, aos textos que estudamos, sobre seu valor de originalidade (...). A indagação só pode ter sentido em séries muito exatamente definidas, em conjuntos cujos limites e domínio foram estabelecidos, entre marcos que limitam campos discursivos suficientemente homogêneos". FOUCAULT, Michel. A arqueologia do saber, p.164.

15 Cf. MARTIN, Hervé. Michel Foucault, penseur de la discontinuité et de la relation. In: BOURDÉ, Guy. e MARTIN, Hervé. (org.). Les écoles historiques. Paris: Editions du Seuil, 1997, p.326.

16 Texto rápido, mas esclarecedor acerca da concepção foucaultiana de história é o trabalho de: HUGHESWARRINGTON, Marnie. Michel Foucault. In: _. . 50 grandes pensadores da História. São Paulo: Contexto, 2004, p.116-124. Ver também: VAN DE WIELLE, Joseph. L'histoire chez Michel Foucault: le sens de l'archéologie. Revue Philosophique de Louvain, Louvain (Belgique), v.81, 1983, p.601-632; O'BRIEN, Patricia. A história da cultura de Michel Foucault. In: HUNT, Lynn. (org.). A nova história cultural. São Paulo: Martins Fontes, 2001; e GRISET, Antoine. Foucault, um projeto histórico. In: VEYNE, Paul et alii. A nova história.

17 Ver: FOUCAULT, Michel. A ordem do discurso. São Paulo: Loyola, 1999, p.55. Texto da aula inaugural proferida no Collège de France, em 1970

18 Ver, em especial, os artigos do dossiê Michel Foucault em: Caminhos da História: Revista da Universidade Estadual de Montes Claros, Montes Claros, MG, v.14, n.2, 2009; e capítulos do livro Epistemologias da história: GIANNATTASIO, Gabriel e IVANO, Rogério. (orgs.). Epistemologias da história: verdade, linguagem, realidade, interpretação e sentido na pós-modernidade. Londrina, PR: Eduel, 2011.

19 Cf. CHARTIER, Roger. A leitura: uma prática cultural. Debate entre Pierre Bourdieu e Roger Chartier. In: (org.). Práticas de leitura, p.242. 
seu criador, intenções conscientes derivadas de uma experiência de vida. Então, as dimensões dos sentidos que uma mens auctoris fixou em um texto, desejando conscientemente atribuir-Ihe um sentido próprio, sempre estará presente no original. Mas perdeu a sua evidência ou, como diria Paul Ricoeur, deixou a sua condição de sentido intentado (o de autor), para assumir novas dignidades de sentido privado (aquele conferido pelos leitores).

Uma reflexão em torno das mutações dos sentidos de um texto foi empreendida por Pierre Bourdieu. O autor francês argumenta que o simples fato de um discurso possuir a sua fixidez na forma de texto impresso faz com que ele sofra alterações e deformações diversas; ainda que, com o passar do tempo, permaneça na exata forma como foi concebido, o texto já mudou. Isso porque sua existência se funda em contatos com o mundo cultural. Se o entorno nunca permanece da forma como está agora, mesmo o texto que permaneceu idêntico a si mesmo já é outro. As alterações surgem ao sabor de novos sentidos que vêm à tona, pois os paladares valorizam a variedade. ${ }^{20}$ Desse modo, parece ter razão quem afirmou que as gerações sucessivas reescrevem a história à sua maneira, ou seja, seguindo os critérios de interesses mutantes em diferentes épocas. ${ }^{21}$ De todo modo, há quem argumente que a interpretação é bem mais um processo de constituição de sentidos. Portanto, é uma operação tão livre e tão subjetiva que, ao constituir sentidos, não é capaz de reconstituí-los. ${ }^{22}$

A irrelevância da figura autoral reconhecida por Michel Foucault ${ }^{23}$ expressa a ideia de que, no trabalho de exegese de um texto, alcançar o sentido original do discurso, em meio à experiência de atores históricos, constitui-se numa tarefa sem finalidade sustentável; a rigor, um texto não desvendará nenhum horizonte muito significativo acerca do autor e seu mundo. Ora, intenções de um autor em seu mundo não formam nenhum ponto culminante quanto às revelações que os textos podem oferecer. Já a análise centrada no texto descobriria progressivamente outros fatores de relevância no campo da história das ideias. Como afirmou François Dosse, a partir de fins dos anos 1960 Foucault firmou uma aliança com os historiadores da nova história, "para desconstruí-la por dentro, à maneira de Nietzsche". ${ }^{24}$ Grande conhecedor da obra de Foucault, Paul Veyne admitiu-se muito impressionado de que, nos livros de Michel Foucault, nos quais existem somente ondas de discurso, só discurso em estado puro e nada além de discurso, onde se

20 A síntese do argumento do autor: "nos esquecemos de que um livro muda pelo fato de que não muda enquanto o mundo muda. Quando o livro permanece e o mundo em torno dele muda, o livro muda". BOURDIEU, Pierre. A leitura: uma prática cultural, p.250.

21 Cf. COLLINGWOOD, Robin George. An Autobiography. Londres: Pelican Books, 1939

22 Ver: GOULEMOT, Jean-Marie. Da leitura como produção de sentidos. In: CHARTIER, Roger. (org.). Práticas de leitura, p.108ss.

23 "Tudo isso é conhecido; faz bastante tempo que a crítica e a filosofia constataram esse desaparecimento ou morte do autor". FOUCAULT, Michel. O que é um autor?, p.269.

24 DOSSE, François. Michel Foucault, estruturalismo e pós-estruturalismo. In: A história à prova do tempo, p.210s 
deixa transparecer que nem mesmo o sexo existe verdadeiramente, ainda se possa distinguir, com evidente clareza, uma história social. ${ }^{25} \mathrm{O}$ próprio Veyne o distingue como "o historiador acabado, o remate da história". 26 Mas tal opinião está longe de formar unanimidade. ${ }^{27}$ Outros historiadores também reconhecem o valor das reflexões de Foucault, em suas contribuições para a história. Segundo as considerações de Jacques Le Goff, os ensinamentos de Michel Foucault convenceram os historiadores acerca do peso e da importância da análise dos discursos, posto que incidem sobre a realidade histórica. Mas o mesmo Le Goff impõe limites às virtudes de suas contribuições, pois descobre no pensamento do autor de $A$ arqueologia do saber a pouca importância conferida aos suportes geradores do discurso: a própria realidade histórica, incluindo nela os autores de textos que, normalmente, conceberam suas obras não por recreação literária ou filosófica, mas muito frequentemente como uma tentativa de interferência, no intuito de mudar algo em seu mundo. ${ }^{28}$ De um modo geral, os discursos políticos, em suas dimensões prescritivas facilmente identificáveis, são depoimentos muito convincentes a esse respeito quando lidos em contraste com o seu próprio tempo. O historiador Robert Darnton chamou a atenção para a evidência de que Foucault e um numeroso grupo de críticos literários transformaram fatos históricos em simples fumaça discursiva. Na condição de historiador, Darnton afirma alinhar-se àqueles que concebem a história "como uma construção imaginativa". Para o historiador norte-americano, a História carece ser pensada e retrabalhada de forma ininterrupta, pois não se pode desconhecer os fatos, poupando-nos do trabalho de "desenterrálos", somente porque alguém disse que tudo é discurso. ${ }^{29}$

Então, se não há propriamente valor na operação intelectual de identificação da autoria de um texto, isto pode significar que o ente gerador de uma dada reflexão, entre outras coisas, tenha sido ineficaz na produção de efeitos. E nesse ponto talvez caiba o ilustrativo exemplo do caso Spinoza. Se de fato as concepções desse célebre filósofo ficaram praticamente des-

25 Cf. VEYNE, Paul. A História: uma paixão nova. In: VEYNE, Paul et alii. A nova história. Lisboa: Edições 70, 1984, p.39. Primeira edição francesa é de 1977. Do mesmo autor, ver ainda: VEYNE, Paul. Foucault, seu pensamento, sua pessoa. Rio de Janeiro : Civilização Brasileira, 2011.

26 E completa numa tirada hiperbólica: "Esse filósofo é um dos grandes historiadores de nossa época, e ninguém duvida disso, mas poderia, também, ser o autor da revolução científica atrás da qual andavam todos os historiadores". VEYNE, Paul. Foucault revoluciona a história. In: __. Como se escreve a história. Brasília: Editora UnB, 1990, p.239.

27 Acerca de Foucault ver, por exemplo, a opinião hostil de: GINZBURG, Carlo. Entrevista. In: PALLARES-BURKE, Maria Lúcia. (org.). As muitas faces da história. São Paulo: Editora Unesp, 2003, p.303. Mas, segundo Winders, "is possible, certainly, to observe the influence of Foucault's ideas and style of historical research on historians and others who have followed after him. His early work exerted a noticeable influence on social and cultural historians of early modern Europe such as Carlo Ginzburg and Natalie Zemon Davis, as well as on historians of the French Revolution such as Lynn Hunt". WINDERS, James. Michel Foucault (1926-1984), p.268.

28 Segundo Jacques Le Goff "continua a ser verdade que nós só podemos verdadeiramente considerar Foucault como um historiador se ele entender que o suporte desse discurso não é inapreensível ou inexistente". Le Goff, Jacques. A História: uma paixão nova. In: Veyne, Paul. et alii, A nova história, p.39s. Acerca das similaridades entre Foucault e os historiadores franceses leia-se HUNT, Lynn. História, cultura e texto. In: __. (org.), A nova história cultural, p.10.

29 Cf. DARNTON, Robert. O beijo de Lamourette. São Paulo: Companhia das Letras, 1998, p.61, p.69. 
conhecidas em seu mundo, qual é o cerne do problema teórico foucaultiano proposto para o estabelecimento de um novo estatuto para a história das ideias? A resposta é que, sendo ineficazes em seu lugar de elaboração, na medida em que não provocaram reações no interior de sua cultura, os textos filosóficos de Spinoza não devem - ou não merecem - ser estudados em relação às circunstâncias que os geraram, porque já nasceram mortos, ou seja, supostamente desprovidos de vínculos com a realidade. Mas, esses mesmos textos, produzidos pelo mesmo filósofo holandês ao longo da segunda metade do século XVII, e que despencaram num vazio desalentador de leitores, passaram a ser objeto de um vivo interesse ao longo do Século das Luzes. Se assim foi, a filosofia de Spinoza só pode ser relevante para o historiador das ideias se for estudada em suas relações com o movimento intelectual do século XVIII, segundo as reações que desencadeou em sua rede de leitores iluministas. Em consequência de tal pressuposto, Spinoza também tornar-se-á objeto de relevo quando leitores da posteridade dos iluministas vierem a estudá-lo por contraste, o que pode gerar outros encadeamentos geracionais. Sob o ângulo da pesquisa de leitor, a reflexão é sustentável, é relevante, e até muito interessante.

Mas, nessa altura, é possível estabelecer um contraponto a tal concepção. O contraponto é justificável por estabelecer uma oposição radical à perspectiva foucaultiana, compondo os fundamentos da pesquisa de autor, conforme se pratica hoje em dia em vários países em que o gênero história das ideias possui tradição consolidada. Com efeito, a matriz de outra ideia de história intelectual - o que alguns designam por pesquisa de autor - foi proposta nos anos 1930 pelo pensador inglês Robin George Collingwood. ${ }^{30}$ A propósito do próprio Spinoza, afirmou Collingwood que este filósofo não deixava de ser um objeto de extremo interesse para o especialista em filosofia seiscentista, não importando se tenham sido suas lições aceitas ou recusadas pelos contemporâneos. O que há de mais relevante é indagar acerca dos fundamentos de sua filosofia, em relação às formas de pensamento e aos sistemas de crenças vigentes no século XVII. Então, garantida desse modo a dignidade do pensamento de Spinoza como objeto legítimo de reflexão histórica, não é tão fundamental assim que Novalis ou Hegel tenham estudado seus textos, para distinguir as lições que puderam extrair deles. Empresa de maior relevo é que nós mesmos, nos dias que correm, possamos estudar Spinoza. Nosso esforço deve concentrar-se na tentativa de repensar a sua filosofia, nos termos em que ele mesmo a pensou. Se assim procedermos com êxito, seremos capazes de apreciar o valor próprio de sua filosofia. Por esse ângulo, a figura do autor tem reconhecida a sua importância central para a pesquisa histórica das ideias já que se trata, em

30 Sob esse aspecto, bastante influenciado pelas reflexões de Benedetto Croce. Refiro especialmente ao impacto, no pensamento histórico de Collingwood, do livro Teoria e Storia della Storiografia, de 1915. 
essência, da reconstituição de uma forma idiossincrática de pensamento, depois de processadas pelas percepções presentes do historiador. Portanto, o valor da pesquisa de autor não está - segundo Collingwood - em estabelecer conexões externas, isto é, que já não mais pertençam ao domínio do autor de um pensamento. ${ }^{31}$

Inspirando-se na imagem do palimpsesto, ideia explorada por escritores modernos desde Poggio Bracciolinni, Michel de Montaigne e Robert Burton, Foucault valoriza as camadas de interpretações acumuladas acerca dos diferentes sentidos que as gerações sucessivas haviam produzido sobre o pensamento original dos autores. Segundo a análise de Montaigne, "interpretar as interpretações dá mais trabalho do que interpretar a própria coisa, mas escrevemos mais livros sobre livros do que sobre os assuntos mesmos; comentamo-nos uns aos outros. Há excesso de comentadores mas escassez de autores". ${ }^{32}$ Nas palavras de Foucault, "Esses autores têm de particular o fato de que eles não são somente os autores de suas obras, de seus livros. Eles produziram alguma coisa a mais: a possibilidade e a regra de formação de outros textos" ${ }^{33}$ Com Foucault, a expressão palimpsesto ganhou um sentido metafórico bem definido. Estudando as práticas discursivas no século XVIII, a partir de uma perspectiva que combinava permanências e rupturas, Michel Foucault observou a sobreposição de valores muito diferentes impregnando a cultura erudita dos homens de letras. No terreno da história natural na época de Lineu e de Buffon ele identificou uma concomitância definida pela recorrência de conexões com as concepções cosmológicas, a história da terra, as Sagradas Escrituras e outras formas de expressões do mundo daqueles tempos. ${ }^{34}$ As formas "alongadas" de noções antigas é um dado constatável empiricamente no século XVIII, época em que se acentuou o processo de dessacralização da história e da política, além de ter promovido outras rupturas sensíveis no campo do saber. Assim sendo, é de se supor que temas políticos antigos se misturassem aos novos ideais que emergiram desde o século XVII. Como o autor declarou em um de seus textos, "uma coisa, em todo o caso, é certa: a arqueologia, dirigindo-se ao espaço geral do saber, a suas configurações, e ao modo de ser das coisas que aí aparecem, define sistemas de simultaneidade, assim como a série de mutações necessárias e suficientes para circunscrever o limiar de uma positividade nova". ${ }^{35}$

Disso parece derivar a ideia do acima referido palimpsesto, expressão utilizada pelo autor de As palavras e as coisas. A rigor, a palavra vem do grego palimpsestos, o que significa "raspado novamente". A reutilização

\footnotetext{
31 Cf. COLLINGWOOD, Robin George. A ideia de história. Lisboa: Editorial Presença, 1981, p.225s.

32 MONTAIGNE, Michel de. Ensaios. São Paulo: Abril Cultural, 1972, p.483.

33 FOUCAULT, Michel. O que é um autor? (1969), p.280.

34 FOUCAULT, Michel. A arqueologia do saber, p.65.

35 FOUCAULT, Michel. As palavras e as coisas. São Paulo: Martins Fontes, 2007, p.12.
} 
de tais suportes por meio de técnicas de raspagem da escrita, com vistas à sobreposição de um novo texto, ficou conhecida como palimpsesto. Em circunstâncias nas quais eram raros os suportes de textos como pergaminho ou papiro, autores foram "guiados" a fixar suas ideias sobre materiais já utilizados, isto é, escreviam por cima. ${ }^{36} \mathrm{Um}$ escritor seiscentista inglês opinou em sentido análogo. No livro A anatomia da melancolia, Robert Burton fez as seguintes referências aos autores de seu tempo, autênticas aves de rapina, incluindo a si mesmo na própria crítica:

Oprimam-se as imprensas, e com o humor sarnento que todo homem tem de se mostrar, desejando fama e honra (...), ele escreverá, haja o que houver, e ajuntará a duras penas, não importa de onde. (...) Escrevem para não dar folga aos tipógrafos ou para atestar que viveram. Como boticários, fazemos novas misturas a cada dia, vertemos de uma vasilha em outra; assim como os antigos romanos saquearam todas as cidades do mundo para adornar Roma, nós coamos a nata do engenho alheio, selecionamos as flores de seus jardins bem cultivados para plantá-las em nossa terra estéril. (...) furtam os antigos escritores para inflarem seus novos comentários, reviram o monturo de Ênio e a cova de Demócrito, como eu. ${ }^{37}$

A partir do comentário de Burton, aqui vem a propósito a crítica histórica corporificada por Leopold von Ranke nos inícios do século XIX. Em As origens trágicas da erudição o historiador Anthony Grafton lembra particularmente uma lição aprendida por Ranke de seu mestre Hermann. Os textos da épica grega passaram por diversas e substantivas remodelações, desde o sexto século até o período helenístico. Ranke percebera então que o que lera de Homero, assim como de vários autores antigos, não havia propriamente surgido de lavras literárias certificadas. O que sobrevivera de Homero fora desfigurado por tradições de leitores que, ao lerem, remodelavam os textos seguindo os interesses particulares de sua época e cultura. Na Atenas de Péricles, por exemplo, a llíada e a Odisseia passaram por interpolações políticas de relevo. ${ }^{38}$ Homero conheceria sucessivas readequações posteriores, algumas vezes para atender também a paladares estéticos. Então, para ler Homero tal qual Homero, seria necessário remover as intenções dos políticos e as invenções dos gramáticos, tarefa um pouco complexa, para não dizer impossível.

Mas, para o analista das ações humanas, aquele que se interessa por identificar o que os autores pretendiam realizar com o seu discurso, em seu

36 Para se compreender tal prática em mosteiros medievais ver a análise de Stephen Greenblatt em seu A virada, obra na qual se narra as aventuras do humanista Poggio Bracciolini em meio ao processo que levou à descoberta do De rerum natura, de Lucrécio. GREENBLATT, Stephen. A virada: o nascimento do mundo contemporâneo. São Paulo: Companhia das Letras, 2012

37 BURTON, Robert. A anatomia da melancolia. Curitiba: Editora UFPR, 2010, p.62ss

38 Cf. GRAFTON, Anthony. As origens trágicas da erudição: pequeno tratado sobre a nota de rodapé. Campinas, SP: Papirus, 1998, p.78. 
próprio tempo, há um vício que marca a forma de abordagem de textos proposta por Michel Foucault. Esse foco centrado exclusivamente no discurso dissolve a própria essência da história: a noção de especificidade do tempo histórico e da singularidade da natureza de uma criação intelectual. Focar um texto como se se tratasse realmente do palimpsesto foucaultiano é admitir a sua "desencarnação" histórica, o seu desenraizamento cultural. Algo como ocorre, por exemplo, nas concepções do historiador norte-americano Arthur Lovejoy. Ele encorpou a teoria de que os sistemas de ideias formavam uma corrente de concepções pela qual os pensadores (elos da referida corrente) retomavam os princípios dos que lhes antecederam no interior de uma tradição filosófica, estabelecendo uma conversação contínua através dos tempos. Na perspectiva de Lovejoy, os pensadores políticos de diferentes épocas estiveram engajados numa relação dialógica acerca de temas comuns e, ao elaborarem seus textos, pensavam bem mais em tais diálogos do que nas circunstâncias de seu mundo histórico. ${ }^{39}$ Pensar dessa forma certamente leva a correr o risco de eliminar a história de personagens históricos afundados até os gorgomilos em processos reais cheios de nuanças, ou seja, também é uma maneira de transformar a história em mera exegese de um texto. ${ }^{40}$ Interpretações que se atenham apenas ao texto são desvios comuns em alguns gêneros de análise histórica. Tais formas de interpretação acabam focando sistematizações teóricas que se esgotam num circuito fechado de ideias, no conhecido mar de discurso, sem que se tente articulá-las ao mundo histórico da obra de pensamento. Em consideração a questões correlatas, Foucault pronunciou-se da seguinte maneira:

É dito, de fato (e é também uma tese bastante familiar), que o próprio da crítica não é destacar as relações da obra com o autor, nem querer reconstituir através dos textos um pensamento ou uma experiência; ela deve analisar a obra em sua estrutura, em sua arquitetura, em sua forma intrínseca e no jogo de suas relações internas. ${ }^{41}$

No plano das teorias de interpretação de textos o foco dos comentários dirigidos contra tais concepções concentrou-se no argumento de que, decretando a morte do autor - rebaixado à categoria de um espectro mudo -, pós-estruturalistas como Foucault pretenderam converter a realidade histórica em texto. Nas palavras de um crítico mais ácido das interpretações textualistas, o filósofo Richard Rorty, intérpretes desta linhagem substituem a

39 Ver a crítica acerca de tal concepção em: SKINNER, Quentin. Meaning and understanding in the History of Ideas. In: TULLY, James. (ed.). Meaning and context: Quentin Skinner and his critics. Cambridge: Polity Press/Basil Blackwell, 1988.

40 Acerca das concepções de Lovejoy ver: GUNNEL, John. Teoria política. Brasília: Editora UnB, 1982. O famoso livro de Arthur Lovejoy, derivado de suas conferências na Universidade de Harvard, em 1923, possui edição brasileira. Ver: LOVEJOY, Arthur. A grande cadeia do ser. São Paulo: Palíndromo, 2005.

41 FOUCAULT, Michel. O que é um autor? (1969), p.269. 
"influência humana" pela "intertextualidade inumana". "A maneira de Foucault lidar com os textos", escreveu Rorty, "é concebida para eliminar totalmente o autor - e, na verdade, a própria ideia de homem" . ${ }^{42}$ Tudo seria texto, e os sentidos atribuídos aos discursos - extraídos de uma gama variada de suportes - eram quase inteiramente livres, mais ou menos ao sabor das suscetibilidades do sujeito do conhecimento. Para ser mais direto: cada leitor produziria a sua própria leitura, a partir daquilo que conseguisse perceber como a mensagem presente nos textos. Isso é possível porque tudo está no texto; não havendo nada fora do texto, tudo o que se afirma ter-se encontrado no interior do texto que não se assemelhe a texto mesmo, na verdade é somente mais texto, haja vista constituir-se este algo além em outra interpretação, afirmou Derrida em sua conhecida Gramatologia. Em sua concepção, a leitura não pode ultrapassar de maneira legítima o texto em relação à outra coisa que não ele próprio. ${ }^{43}$ As análises do discurso que surgem dessas formas de abordagem normalmente podem até se constituir em leituras intertextuais sofisticadas, mas frequentemente serão abordagens a-históricas. Como disse Michel Winock,

o importante não é insistir na causalidade dos fenômenos, mas tornar inteligível seu funcionamento, os elos de reciprocidade entre os componentes, os acordos intrínsecos à organização, a estrutura. O sistema, assim definido, não por sua gênese, mas pelas redes relacionais, as relações de dependência mútua entre os elementos, as variações e as diferenças, é, por seu método, uma outra maneira de esvaziar a história. ${ }^{44}$

A esse propósito, alguém definira o sistema foucaultiano como uma "geometria abstrata" ou então como uma "maquinaria sem maquinista". Jacques Léonard retratou-o como um hábil construtor de hipóteses. Contudo, e mesmo que se considere toda a sua capacidade inventiva, ele caminha pela história a passos demasiadamente largos, não sendo capaz de construir uma obra estável; não se aplica ao estudo das evidências documentais, no sentido de desvendar os acontecimentos que os textos relatam acerca de um dado momento, de um dado horizonte temporal. ${ }^{45}$ Em texto claramente laudatório, muito aplicado em compor o discurso das grandezas do filósofo, Jacques Revel nos faz recordar as reações de

42 RORTY, Richard. O idealismo do século XIX e o textualismo do século XX. In: __. Consequências do pragmatismo. Lisboa: Instituto Piaget, s.d., p.228.

43 "ne peut légitimement transgresser le texte vers autre chose que lui, vers un référent - réalité métaphisyque historique, psycho-biographique etc. - ou vers un signifié hors texte dont le contenu pourrait avoir lieu, aurrait pu avoir lieu hors de la langue, c'est-à-dire, au sens que nous donnons ici à ce mot, hors de l'écriture en général". DERRIDA, Jacques. De la grammatologie. Paris: Minuit, 1967, p.227.

44 WINOCK, Michel. O século dos intelectuais. Rio de Janeiro: Imago, 2000, p.707s.

45 Nas palavras de Léonard: "C'est un 'cosaque de l'histoire', qui aime les grandes chevauchées (il 'parcourt trois siècles, à bride abattue, comme un cavalier barbare'), et dont les irruptions dans le champ historique ont quelque chose de dévastateur, même si la fécondité de certaines de ses hypothèses est incontestable". Citado por: MARTIN, Hervé. Michel Foucault, penseur de la discontinuité et de la relation, p.328. 
Foucault contra os que o acusaram de "escrever a história da loucura sem a presença dos loucos, a da prisão sem os prisioneiros, a da sexualidade, por fim, evitando os corpos". ${ }^{46}$

Para os críticos de Foucault, se o círculo hermenêutico não se processa em torno do homem e da obra, se os fundamentos de um texto não carecem de um enquadramento do contexto de um autor, se as circunstâncias do processo intelectual, na origem, podem ser dispensadas, pois não representam um interesse decisivo, se tais elementos não devem concorrer para a análise do discurso, haverá uma profunda carência de fundamentos históricos nas análises que se instaurem sobre tais lacunas. Lucien Goldmann, nos comentários críticos que fez à conferência proferida por Michel Foucault no Collège de France, em 1969, pronunciou-se nos seguintes termos:

Após um certo número de anos, toda uma série de análises concretas mostrou de fato que, sem negar nem o sujeito nem o homem, se é obrigado a substituir o sujeito individual por um sujeito coletivo ou transindividual. Em meus próprios trabalhos, fui levado a mostrar que Racine não é sozinho o único e verdadeiro autor das tragédias racinianas, mas que estas nasceram no bojo do desenvolvimento de um conjunto estruturado de categorias mentais que era obra coletiva, o que me levou a encontrar como 'autor' dessas tragédias, em última instância, a nobreza de toga, o grupo jansenista e, no interior deste, Racine como indivíduo particularmente importante. ${ }^{47}$

Levando adiante seu comentário a Foucault, o autor complementa sua análise com a imagem bifronte de Pascal que, segundo Goldmann, seria autor duplo de uma dupla obra. Ao analisar o conceito de "obra", ele afirma ser Les provinciales e Pensées, ambas de Pascal, de autorias distintas. Uma vem do Pascal como membro dos jansenistas moderados e a outra dos jansenistas extremados. E conclui: "Dois autores diferentes, que têm um setor parcial comum: o indivíduo Pascal e talvez alguns outros jansenistas que tiveram a mesma evolução". ${ }^{48}$ Mas Goldmann não vai além dessas confluências, desconsiderando o papel da autoria. Para ele, sempre houve ou existirá uma realidade fora do texto a requerer parcela substancial da atenção dos historiadores. Então, cabe distinguir que, se um documento histórico, de qualquer natureza, deve ser apreendido pelo historiador como algo que nunca representa a verdade - é apenas uma representação de realidades contingentes e, portanto, um monumento da capacidade de representação humana - o discurso define algo assim como a "alma" do texto: uma matéria que apenas tornar-se-á legível pelo esforço da operação interpretativa. Como afirma Ricoeur, o estruturalismo tende a estudar a

\footnotetext{
46 Ver os termos de tal defesa em: REVEL, Jacques. Foucault, Michel, 1926-1984. In: BURGUIÈRE, André. (org.). Dicionário das ciências históricas. Rio de Janeiro: Imago, 1993, p.339.

47 Intervenção de GOLDMANN, Lucien. In: FOUCAULT, Michel. O que é um autor? (1969), p.290.

48 GOLDMANN, Lucien. In: FOUCAULT, Michel. O que é um autor? (1969), p.290.
} 
linguagem poupando o sujeito, a ação, os eventos. ${ }^{49} \mathrm{~A}$ história intelectual, segundo a defesa que fazem dela historiadores que reagem criticamente às visadas pós-estruturalistas, investe na capacidade do sujeito em situar-se como personagem atuante no mundo, como um agente ativo que se opõe a interlocutores tão reais como ele mesmo em meio a determinadas circunstâncias, como um coeficiente de força que tenciona atingir um alvo em sua existência histórica concreta. ${ }^{50} \mathrm{~A}$ análise interpretativa de textos formulada por Michel Foucault opõe-se à perspectiva de que a compreensão de um texto implique em qualquer tentativa de reconstituição de pensamentos ou intenções originais de qualquer personalidade histórica datada, como pretendia, por exemplo, a teoria de Robin George Collingwood. ${ }^{51}$ Já Ricoeur argumenta que o discurso, quando passa de uma situação oral para uma condição de texto, perde nesse processo todas as suas implicações dialógicas de origem. O dito original torna-se algo fossilizado e deixa de pertencer ao horizonte histórico do autor. Para Ricoeur, ao desvincular-se de seu local de formulação, o discurso passa a possuir uma audiência própria e é mais importante decifrar nele o que ele efetivamente diz do que aquilo que ele pretendia dizer. É assim que o texto se abre inteiramente a qualquer intérprete, nos limites de sua possibilidade de produzir sentidos, como se possuísse "significados privados", aqueles sentidos subjetivos que são estabelecidos mais ou menos livremente.

Com tais margens, e ainda que se lance o alerta de que um texto, podendo permitir diferentes interpretações, não autoriza qualquer interpretação, a liberdade para a descoberta de mensagens é de fato bem extensa. O discurso fixado no suporte página manuscrita ou impressa, escapando dos horizontes circunscritos do autor (a menos que seja "uma algaravia datilografada ao acaso por um macaco", na expressão de Paul Veyne), tornar-se-á obra aberta entre leitores diversos. Dessa forma, não se reconhecerá como uma dimensão relevante presente no discurso quaisquer intenções externadas por um autor. Mas se no campo das interpretações essas disposições de princípios geram efeitos positivos, também acarretam complicações, como a dificuldade do pesquisador discernir quais recursos teóricos são adequados a este ou àquele gênero de pesquisa. Contudo, uma evidência salta aos olhos: a de que a exegese textual, sendo composta por múltiplos interesses e diferentes enquadramentos teóricos, não está mais unificada por conceitos e concepções que a reduzam a um gênero único

49 Cf. RICOEUR, Paul. Em torno ao político. São Paulo: Loyola, 1997, v.1.

50 Acerca dessa perspectiva, ver os títulos recentemente lançados no Brasil: SKINNER, Quentin. Maquiavel. Porto Alegre: L\&PM, 2010; SKINNER, Quentin. Hobbes e a liberdade republicana. São Paulo: Editora Unesp, 2010.

51 Ver os princípios fundantes de suas concepções em: DRAY, Willian. Filosofia da História. Rio de Janeiro: Zahar Editores, 1977; RIDLEY, Aaron. R.G. Collingwood. São Paulo: Editora Unesp, 2001; e HUGHES-WARRINGTON, Marnie. R.G. Collingwood. In: . 50 grandes pensadores da História, p.60-68. 
e monocórdio. ${ }^{52}$ Como observou Michel Foucault, "não é fácil caracterizar uma disciplina como a história das ideias: objeto incerto, fronteiras mal desenhadas, métodos tomados de empréstimo aqui e ali, procedimento sem retitude e sem fixidez". ${ }^{53}$

Apesar de terem emergido, em torno ao seu pensamento, numerosos simpatizantes entusiasmados, alguns atuando como os representantes legais e intérpretes oficiais do cânone, nada mais distante de Michel Foucault do que a ortodoxia. De fato, formam volume expressivo os que desejam fazer crer que o multifacetado pensamento histórico de Foucault possui uma chave mágica somente para iniciados. E as relações com o pensamento de Foucault por vezes alcançam planos de religiosidade substitutiva. Ora, dos historiadores das ideias espera-se hoje em dia que pensem formas diversas de racionalidade no tempo, mantendo um distanciamento reflexivo e empático diante da diversidade das formas de abordagem. Uma obra da envergadura daquela construída pelo pensador francês, junto com os fundamentos virtuosos que abriga, carrega também as suas, digamos, "impurezas". Esses resíduos podem ser aspectos como os acima definidos no campo da interpretação de textos. Mas há também quem se esforce em fazer crer na existência de uma unidade, impondo vista grossa à trajetória errática, que mudou ao sabor de fases e experiências acumuladas pelo autor ao longo de algumas décadas de intensa atividade intelectual. E no vasto universo foucaultiano (que ainda se expande entre nós), ninguém melhor para negar certas convicções enrijecidas do que o próprio Foucault.

Alcançados pelas críticas dos que procuraram por unidade ou coerência na obra do filósofo, sem encontrá-las em suficiente medida, os defensores de Foucault por vezes tentaram demarcar em seu pensamento alguns contornos supostamente visíveis e palpáveis, no sentido de acomodar variações talvez indesejadas. Mas qual o propósito de se constituir em torno de um pensamento uma ideia de conjunto, quando a fragmentação aparece em várias partes? A rigor, não há desmerecimento no fato de dado autor (qualquer autor), em algum momento de sua atividade intelectual, deixar de concordar consigo mesmo, total ou parcialmente e, sobretudo, no decorrer de uma longa e intensa trajetória intelectual. Antes pelo contrário, há mérito em tais guinadas do pensamento, pois são naturais e até necessárias, visto que contribuem para preservar por mais tempo a vitalidade de uma reflexão sempre em curso: a de um Foucault inacabado. Aliás, como apontou François Dosse, muito difícil a tarefa de caracterizar Michel Foucault como um pensador pós-estruturalista haja vista que ele "nunca parou de desprender-

52 Sobre a temática, ver as análises de: DAVIDS,ON, Arnold. Foucault et l’analyse des concepts. In: FRANCE, Dominique et alli. Au Risque de Foucault. Paris: Éditions du Centre Pompidou, 1987.

53 FOUCAULT, Michel. A arqueologia do saber, p.156. 
se de si mesmo. Daí a importância da historicização de sua obra". ${ }^{54}$ Se determinados autores - e Foucault incluído entre eles -, estabeleceram em algum ponto do passado relações com diferentes correntes teóricas - para mais tarde renegá-las até com veemência -, isso não deveria significar que se interdite caracterizá-los como marxistas, como estruturalistas etc., naqueles pontos específicos de suas experiências de vida. E se também determinados autores renegam veementemente algumas qualificações advindas ou não de campos de oposição - como Foucault não admitiria para si a distinção de pós-moderno, por exemplo -, isso não deveria bloquear por parte de seus críticos a referida qualificação, sob pena de tencionarem "transformar" Foucault em algo não admitido por ele mesmo. ${ }^{55}$ Ora, se os críticos de Foucault o denominam um pensador pós-estruturalista, pósmodernista etc., é porque pensam ter encontrado em seu pensamento, e em seus textos, os indícios para tanto, ainda que tal atitude algum dia tenha descontentado o próprio autor, e os guardiões de seu templo. Se de fato há denso corpo canônico a definir o que pode e o que não pode ser conceitos como pós-moderno, a vasta literatura consagrada ao tema ainda não se estabeleceu uma sentença final a respeito, e é preciso que reine um pouco de liberdade neste território. Isso para dizer que aproximações exploratórias e afastamentos críticos diante de temas, de conceitos e de enquadramentos teóricos compõem a navegação tortuosa de pensadores do calibre de Michel Foucault. Desse modo, a erraticidade, a escassez de unidade, a linguagem cifrada, enfim, "a anarquia ordenada" da qual ele mesmo se orgulhava formam, no meu modo de entender, algumas das dimensões da referida pós-modernidade foucaultiana.

A ironia que Foucault dirigiu aos críticos retrata muito bem a sua capacidade em zombar dos outros, rindo também um pouco de si ao cismar, em certa passagem, ser apenas mais um historiador convencional de ideias, apanhadas no tempo de forma dura e seca, desprovidas de referências a uma linguagem específica e a uma experiência singular no tempo; não mais do que um historiador de ideias, de pensamentos, ou de discursos, o que não modifica a natureza da matéria-prima (leia-se fontes) por ele utilizada. Se o autor diferenciou sua "arqueologia" do modelo formal de "história das ideias", no claro intuito de promover a antiga tópica "Trago novidades", não deixou de entregar uma história dos discursos, assentando suas análises em documentação variada, incluindo obras de pensamento. Essas são os pilares das diversas linhagens de história intelectual. ${ }^{56}$ Foucault caiu, assim,

54 DOSSE, François. Michel Foucault, estruturalismo e pós-estruturalismo, p.195.

55 Pareceu-me ser dessa natureza o comentário tecido por Durval Muniz de Albuquerque Júnior a Ronaldo Vainfas, Ciro Cardoso, e Jurandir Malerba. Ver: ALBUQUERQUE JÚINIOR, Durval. Entre luzes e sombras: Michel Foucault, um pensador pós-moderno? Caminhos da História. Revista da Universidade Estadual de Montes Claros, v.14, n.2, p.12, 2009.

56 Como afirma Chartier, as historiografias nacionais são detentoras de conceituações específicas e particulares a cada tradição. E mesmo no interior de cada uma delas competem distintas perspectivas, que se embaralham 
e mesmo tencionando demarcar suas inovações, em um gênero de história que possui inúmeras variações quanto ao "modo de fazer". Se detivermos a liberdade de analisar o autor por fora de suas façanhas criadoras (as que ele quis fazer crer que engendrou de modo original, na qualidade de inventor filosófico), não será preciso aceitar apenas o que ele disse acerca de si mesmo, a partir da autocompreensão de apenas certas passagens "selecionadas" de sua obra. Numa leitura sobre o pensamento histórico é preciso evitar impregnações doutrinais ou outras formas de miopia tão comuns nesta esfera. Do contrário, corre-se o risco de atribuir a Foucault a dignidade de oráculo sagrado, o que evidentemente seria muito difícil de explicar.

umas nas outras. E isso de tal modo que a história intelectual ou das ideias não se constitui em uma disciplina autônoma. Seus objetos ou métodos, a rigor, não existem. Prova disso são as variações das abordagens que se ancoram em seu porto. Ver: CHARTIER, Roger. História Intelectual. In: BURGUIĖRE, André. Dicionário das ciências históricas, p.447ss. Ver, também, as considerações tecidas em dois ensaios de: DARNTON, Robert. História intelectual e cultural; História social das ideias. In: O beijo de Lamourette, p.175ss e p.198ss. 